ORIGINAL ARTICLE

\title{
Association of Peripheral Neuropathy in Hepatitis C Infection with and without Cryoglobulineamia
}

\author{
ASMAT ULLAH ${ }^{1}$, MIRWAIS KAKAR ${ }^{2}$, BILAL AHMED ${ }^{3}$, SADIA JABBAR $^{4}$, INAYAT ULLAH ${ }^{5}$ \\ ${ }^{1}$ Assistant Professor Gastroenterology, Gambat Institute of Medical Sciences, Khairpur Sindh \\ ${ }^{2}$ Senior Registrar Gastroenterology, Bolan Medical Complex Hospital, Quetta \\ ${ }^{3}$ Assistant Professor Liver Transplant Unit, Gambat Institute of Medical Sciences Khairpur Sindh \\ ${ }^{4}$ Senior Registrar Gastroenterology, Lahore General Hospital, Lahore \\ ${ }^{5}$ Senior Registrar Gastroenterology, Bolan Medical Complex Hospital, Quetta \\ Corresponding author: Dr Asmat Ullah, Email: asmat.shahwani9@gmail.com, Cell No: 03234998550
}

\begin{abstract}
Objective: The purpose of this study was to find out the association of peripheral neuropathy in hepatitis $\mathrm{C}$ infection with and without cryoglobulineamia.

Study Design: Cross sectional study

Place and Duration: Conducted in Liver Transplant Unit, Gambat Institute of Medical Sciences, Gambat Khairpur Mirs, Sindh for the duration of six months from November 2020 to April 2021.

Methods: Total 50 patients who had hepatitis $\mathrm{C}$ infection and peripheral neuropathy were included in this study. Patients were aged between 18- 60 years. Detailed demographics of patients including age, sex and body mass index were recorded after taking informed written consent. When symptoms and evidence of peripheral sensory or motor involvement were evident, clinical neuropathy was diagnosed. Sural nerve biopsy was done on patients and the biopsy specimen was evaluated morphologically and morphometrically. Multiple neuropathy, cranial neuropathy, and polyneuropathy are all terms used to describe peripheral nerve involvement. Our research focused on the motor conduction of the median, ulnar, and common peroneal nerves, measuring MCV, CMAP amplitude, and distal latency (DL) in both patients with and without cryoglobulinaemia for each nerve. The SPSS 20.0 version was used to analyze the data.

Results: Mean age of the patients was $46.23 \pm 9.87$ years with mean BMI $29.16 \pm 11.27 \mathrm{~kg} / \mathrm{m}^{2}$. There were 30 $(60 \%)$ females and $20(40 \%)$ were males. We found that $35(70 \%)$ patients had CG involvement with peripheral neuropathy and $15(30 \%)$ cases were without CG. Prevalence of polyneuropathy was higher $19(54.3 \%)$ in CG patients as compared to non CG 2 (13.3\%). Mononeuropathy or multiple neuropathy was higher in HCV CG patients $13(37.1 \%)$ as compared to HCV non CG patients $4(26.7 \%)$. 25 patients underwent nerve biopsy (20 CG patients and 5 non CG). Prevalence of epineurial vasculitis and fascicular loss of axons was higher in non CG patients while demyelination + axonal degeneration were prevalent in CG patients. MCV of the deep peroneal nerve in patients with CG+ was low as compared to CG. Even though no statistically significant differences were detected, the other neurophysiological measures pointed to a more extensive and severe involvement of peripheral nerve in $\mathrm{CG}+$ patients.

Conclusion: We concluded in this study that the association of peripheral neuropathy in HCV patients with cryoglobulinaemia was greater as compared to non-CG HCV patients. It appears that both $\mathrm{CG}+$ and $\mathrm{CG}$ patients suffer from peripheral nerve injury via a vasculitic mechanism, as evidenced by clinical and morphological observations. Serum CG levels indicate a more severe and broad neuropathic involvement, however research suggests that cryoglobulins are not the only element in the vasculitic process.
\end{abstract}

Keywords: Cryoglobulinemia, Peripheral Neuropathy, HCV

\section{INTRODUCTION}

This virus can be transferred via parenteral means and infects the liver as well as the lymph nodes. Cirrhosis, hepatocellular carcinoma, and chronic hepatitis are all directly linked to HCV infection in roughly 170 million persons around the world [1]. Extrahepatic symptoms may include mixed cryoglobulinemia, lymphoproliferation, and membranoproliferative glomerulonephritis, as well as sicca syndrome, porphyria cutanea tarda (a skin disease), thyroiditis, and peripheral neuropathy (PN). [2] In addition to subacute, distal sensory-motor polyneuropathy usually associated with CG, mono- and multiple-neuritis have also been described. [3-5]

Inflammatory vascular lesions linked with HCV are thought to be caused by vascular deposition of HCV RNA carrying $\mathrm{Cg}[6,7]$ or by perivascular mononuclear inflammation cells[8,9]. The pathophysiology of HCVrelated $\mathrm{PN}$ is still largely unclear. Rather than a direct nerve infection and in situ replication, HCV neuropathy is most likely caused by virus-triggered immune mediated mechanisms. [10] Only a few papers have looked at the prevalence of $\mathrm{PN}$ in an unselected $\mathrm{HCV}$ population to better understand the clinical and electrophysiological spectrum of HCV-associated PN. [11,12]

Many EHMs are immunologic/rheumatologic in nature, as a result of $\mathrm{B}$-cell proliferation with subsequent generation of monoclonal and polyclonal autoantibodies displaying rheumatoid factor activity or cryoglobulin features [13]. This includes a number of neurological disorders. According to findings from quasispecies analysis and the discovery of replicative intermediate forms of the human cytomegalovirus (HCV) RNA and viral proteins in the brain, the central nervous system (CNS) may be a permissive region for viral reproduction. Circulating inflammatory cytokines and chemokines reaching brain tissues via altered blood-brain barrier locations may have 
additional pathways contributing to neurological impairment. As many as $50 \%$ of $\mathrm{HCV}$-infected patients have cryoglobulinemia, the most common and best-studied EHM of HCV infection, causing symptoms in almost $15 \%$ of cases. These cold-precipitable immunoglobulins, known as cryoglobulins (CGs), cause inflammation and blood vessel blockage after vascular deposition.[14]

Chronic infections, autoimmune illnesses, and lymphoproliferative diseases all have CG as a component [15]. Patients with chronic HCV infection or primary Sjögren syndrome often have type I CG, which is monoclonal Ig (10-15 percent of the time). Patients with lymphoproliferative disorders, chronic infections, and autoimmune diseases, on the other hand, are more likely to have type II CG, which is a mixture of monoclonal Ig rheumatoid factor and polyclonal lgG (50-60 percent). Type II and III CG, also known as "mixed CG" (MC), are nearly always the result of long-term HCV/HIV infection. Lymphocytic microvasculitis and/or necrotizing arteritis are secondary mechanisms that cause CG-induced ischemic tissue damage. This results in transmural fibrinoid necrosis and polymorphonuclear cell infiltration. Skin purpura, arthritis, peripheral neuropathy, and membranous proliferative glomerulonephritis are common symptoms of CG $[15,17]$.

Most individuals with CG develop peripheral neuropathy within the first few months after diagnosis, with CNS involvement occurring in just about $6 \%$ of cases. Carotid plaque development, hepatic fibrosis, and liver steatosis are also possible side effects of CGs in addition to vascular damage. NHL, diabetes, thyroid disorders, and rheumatological diseases are less common EHMs of HCV infection that provide a risk of brain involvement. Importantly, antiviral treatment can improve or even resolve most EHMs, particularly in those who have had a persistent virological response to the virus.

We looked at a group of $50 \mathrm{HCV}$ neuropathic patients in order to identify the prevalence of $\mathrm{CG}$ and to better understand the pathogenetic process by which $\mathrm{HCV}$ causes PN.

\section{MATERIAL AND METHODS}

This cross sectional study was conducted at Liver Transplant Unit, Gambat Institute of Medical Sciences, Gambat Khairpur Mirs, Sindh for the duration of six months from November 2020 to April 2021. The study consisted of $50 \mathrm{HCV}$ patients. Demographical baseline details of patients including age, sex and body mass index were recorded after taking informed written consent. Patients who had diabetes mellitus, renal failure, thyroid disorder, alcohol abuse, neoplasm including hepatocellular carcinoma, toxicity and those who did not give any written consent were excluded from this study.

Patients were aged between 18-60 years. Median, ulnar, peroneal, and sural nerves were explored in all patients and distal symmetric polyneuropathy was diagnosed when all explored nerves or both lower limb nerves were affected. When symptoms and evidence of peripheral sensory or motor involvement were evident, clinical neuropathy was diagnosed. Sural nerve biopsy was done on patients, and the biopsy specimen was evaluated morphologically and morphometrically. Multiple neuropathy, cranial neuropathy, and polyneuropathy are all terms used to describe peripheral nerve involvement. Using an enzyme linked immunosorbent assay and a more specific recombinant immunoblot assay, all of the patients tested positive for anti-HCV serum antibodies. Cryoglobulins were detected and characterized in laboratory studies that included regular blood testing, immunological assays (the latex test for IgM rheumatoid factor, $\mathrm{C} 4$ values, and autoantibodies). 1 Cryoglobulin determined by a minimum of three measurements were made during the course of the investigation.

Standard electromyographic equipment was used by a single operator to conduct electrodiagnostic examinations. All patients had their sensory conduction along the median and ulnar nerves examined. Scanners measured the speed of sensory conduction (SCV) and the magnitude of sensory action potentials (SAPs) in each nerve. The magnitude of low-amplitude sensory responses was calculated via computer averaging. A motor conduction study was conducted on nerves of the median and ulnar, as well as the common peroneal, to determine the speed at which the nerves conduct electrical impulses (DL). $\mathrm{F}$ waves are used to detect changes in the proximal conduction. We'll go with one with the shortest $F$ wave latency. SPSS 20.0 version was used to analyze the complete data.

\section{RESULTS}

We found that 35 (70\%) patients had CG involvement with peripheral neuropathy and $15(30 \%)$ cases were without CG. Mean age of the patients was $46.23 \pm 9.87$ years with mean BMl $29.16 \pm 11.27 \mathrm{~kg} / \mathrm{m}^{2}$. There were $30(60 \%)$ females and 20 (40\%) were males. There was no any significant difference in age and BMl in CG and non CG patients. Prevalence of polyneuropathy was higher 19 (54.3\%) in CG patients as compared to non CG 2 (13.3\%). Mononeuropathy or multiple neuropathy was higher in HCV CG patients $13(37.1 \%)$ as compared to HCV non CG patients $4(26.7 \%)$ while cranial neuropathy and polyneuropathy + cranial neuropathy was prevalent in non CG patients (40\% and $20 \%$ ) and in CG patients $(5.7 \%$ and $2.9 \%$ ). HCV CG+ patients showed significantly higher proportion of rheumatoid factor positivity and low C4 levels $(p=0.003) .($ Table 1$)$

\begin{tabular}{l} 
Table 1: Demographically details with clinical and laboratory data \\
\begin{tabular}{|l|l|l|}
\hline Variables & CG patients & $\begin{array}{l}\text { Non- CG } \\
\text { patients }\end{array}$ \\
\hline Frequency & $35(70 \%)$ & $15(30 \%)$ \\
\hline Mean age (years) & $46.23 \pm 9.87$ & $46.02 \pm 7.23$ \\
\hline Mean BMI (kg/m²) & $29.16 \pm 11.27$ & $29.13 \pm 8.22$ \\
\hline Gender & $15(30 \%)$ & $5(10 \%)$ \\
\hline Male & $20(40 \%)$ & $10(20 \%)$ \\
\hline Female & $19(54.3 \%)$ & $2(13.3 \%)$ \\
\hline Clinical data & $13(37.1 \%)$ & $4(26.7 \%)$ \\
\hline polyneuropathy & $2(5.7 \%)$ & $6(40 \%)$ \\
\hline multiple neuropathy & $1(2.9 \%)$ & $3(20 \%)$ \\
\hline cranial neuropathy & \multicolumn{2}{|l|}{} \\
\hline $\begin{array}{l}\text { polyneuropathy + cranial } \\
\text { neuropathy }\end{array}$ & $32(91.4 \%)$ & $3(20 \%)$ \\
\hline Laboratory data & $30(85.7 \%)$ & $8(53.3 \%)$ \\
\hline Low C4 levels & $24(68.6 \%)$ & $7(46.7 \%)$ \\
\hline Rheumatoid factor positive & \\
\hline Transaminase activity increase &
\end{tabular} \\
\hline
\end{tabular}


25 patients had undergone nerve biopsy (20 CG patients and 5 non CG). Prevalence of epineurial vasculitis and fascicular loss of axons was higher in non CG patients while demyelination + axonal degeneration were prevalent in CG patients. (Table 2)

Table 2: Association of morphological data (frequency of biopsies)

\begin{tabular}{|l|l|l|}
\hline Variables & $\begin{array}{l}\text { CG patients } \\
(\mathbf{n}=35)\end{array}$ & $\begin{array}{l}\text { Non- CG patients } \\
(\mathbf{n}=\mathbf{1 5})\end{array}$ \\
\hline Biopsy & $20(57.1 \%)$ & $5(33.3 \%)$ \\
\hline Yes & $15(42.9 \%)$ & $10(66.7 \%)$ \\
\hline No & $15(42.8 \%)$ & $9(53.3 \%)$ \\
\hline Morphological data & $12(34.3 \%)$ & $6(40 \%)$ \\
\hline Epineurial vasculitis & $\begin{array}{l}\mid \\
\text { Differential fascicular loss of } \\
\text { axons }\end{array}$ & $1(6.7 \%)$ \\
\hline $\begin{array}{l}\text { Demyelination + axonal } \\
\text { degeneration }\end{array}$ & $8(22.9 \%)$ & \\
\hline
\end{tabular}

MCV of the deep peroneal nerve in patients with $\mathrm{CG}+$ was low as compared to non CG. Even though no statistically significant differences were detected, the other neurophysiological measures pointed to a more extensive and severe involvement of peripheral nerve in $\mathrm{CG}_{+}$ patients. (Table 3 )

Table 3: Sensory and motor nerve conduction in all patients

\begin{tabular}{|c|c|c|}
\hline Variables & CG patients & Non- CG patients \\
\hline \multicolumn{3}{|c|}{ Deep peroneal nerve } \\
\hline $\operatorname{MCV}(\mathrm{m} / \mathrm{sec})$ & $44.23 \pm 9.87$ & $49.18 \pm 8.78$ \\
\hline $\mathrm{DL}(\mathrm{m} / \mathrm{sec})$ & $7.5 \pm 3.8$ & $7.2 \pm 3.8$ \\
\hline $\mathrm{Amp}(\mathrm{mV})$ & $6.4 \pm 3.4$ & $8.6 \pm 3.2$ \\
\hline $\mathrm{F}$ wave $(\mathrm{m} / \mathrm{sec})$ & $45.12 \pm 7.66$ & $41.16 \pm 7.33$ \\
\hline \multicolumn{3}{|l|}{ Median nerve } \\
\hline $\mathrm{MCV}(\mathrm{m} / \mathrm{sec})$ & $54.21 \pm 5.43$ & $54.20 \pm 5.20$ \\
\hline $\mathrm{DL}(\mathrm{m} / \mathrm{sec})$ & $5.3 \pm 1.2$ & $5.11 \pm 1.6$ \\
\hline$A m p(m V)$ & $19.3 \pm 7.34$ & $13.6 \pm 4.71$ \\
\hline \multicolumn{3}{|l|}{ Ulnar nerve } \\
\hline $\mathrm{MCV}(\mathrm{m} / \mathrm{sec})$ & $56.9 \pm 8.45$ & $57.17 \pm 3.44$ \\
\hline $\mathrm{DL}(\mathrm{m} / \mathrm{sec})$ & $3.2 \pm 4.5$ & $3.0 \pm 5.4$ \\
\hline$A m p(m V)$ & $15.12 \pm 6.25$ & $15.97 \pm 6.31$ \\
\hline F wave $(\mathrm{m} / \mathrm{sec})$ & $25.32 \pm 3.22$ & $24.88 \pm 3.45$ \\
\hline \multicolumn{3}{|l|}{ Sural nerve } \\
\hline $\mathrm{SCV}(\mathrm{m} / \mathrm{sec}$ & $44.1 \pm 8.11$ & $45.3 \pm 5.32$ \\
\hline SAP ampl (mcV) & $7.13 \pm 3.17$ & $11.23 \pm 2.43$ \\
\hline \multicolumn{3}{|l|}{ Median nerve } \\
\hline W-F SCV $(\mathrm{m} / \mathrm{sec}$ & $52.4 \pm 8.4$ & $51.6 \pm 9.5$ \\
\hline SAP ampl. (mcV) & $30.7 \pm 4.8$ & $35.2 \pm 6.2$ \\
\hline E-W SCV $(\mathrm{m} / \mathrm{sec})$ & $56.3 \pm 3.7$ & $59.3 \pm 2.9$ \\
\hline SAP ampl (mcV) & $11.1 \pm 4.8$ & $15.3 \pm 6.4$ \\
\hline \multicolumn{3}{|l|}{ Ulnar nerve } \\
\hline $\mathrm{SCV}(\mathrm{m} / \mathrm{sec})$ & $54.1 \pm 4.7$ & $53.2 \pm 6.2$ \\
\hline SAP ampl (mcV) & $31.4 \pm 9.3$ & $39.3 \pm 8.5$ \\
\hline
\end{tabular}

We observed a substantial fibre loss in CG+ compared with CG- patients ( $p<0.005$, $t$ test), as well as in percentage of big myelinated fibres ( $p<0.005$, $t$ test). Total number of clusters, signifying regenerated fibres, was significantly enhanced in CG- compared with $\mathrm{CG}_{+}$individuals. (Table 4)

Table 4: Association of sural nerve biopsy specimens (histometry)

\begin{tabular}{|l|l|l|}
\hline Variables & CG patients & Non- CG patients \\
\hline Fibre density $(\mathrm{n} / \mathrm{mm} 2)$ & $3.322 \pm 4.721$ & $5.265 \pm 3.876$ \\
\hline Fibres $>8 \mu \mathrm{m}(\%)$ & $10.8 \pm 3.12$ & $22.4 \pm 6.14$ \\
\hline number of clusters & $20.5 \pm 3.65$ & $87.9 \pm 3.33$ \\
\hline
\end{tabular}

\section{DISCUSSION}

In HCV-infected patients, the PNS is damaged in a variety of ways, mostly because of the presence and type of CG, as well as other co-morbidities and iatrogenic variables that are present. Since type I CG with HCV involvement is extremely rare, the pathogenesis is still a mystery. However, our observations are in line with axonal polyneuropathy, which is characterized by perivascular infiltrates, endoneurial purpura, and microangiopathy. These findings suggest an ischemic pathogenesis linked to endoneurial microcirculation obstruction [18].

In this cross-sectional study 50 patients of both genders were presented. Mean age of the patients was $46.23 \pm 9.87$ years with mean BMl $29.16 \pm 11.27 \mathrm{~kg} / \mathrm{m}^{2}$. Majority of the patients $30(60 \%)$ were females and 20 $(40 \%)$ were males. We found that $35(70 \%)$ patients had CG involvement with peripheral neuropathy and $15(30 \%)$ cases were without CG. These findings were comparable to the previous studies.[19,20] Prevalence of polyneuropathy was higher $19(54.3 \%)$ in CG patients as compared to non CG 2 (13.3\%). Mononeuropathy or multiple neuropathy was higher in HCV CG patients 13 (37.1\%) as compared to HCV non CG patients 4 (26.7\%) while cranial neuropathy and polyneuropathy + cranial neuropathy was prevalent in non CG patients $(40 \%$ and $20 \%$ ) and in CG patients (5.7\% and $2.9 \%$ ). HCV CG+ patients showed significantly higher proportion of rheumatoid factor positivity and low C4 levels $(p=0.003) \cdot[19,21]$ In addition, Lidove found that a large percentage of HCV CG patients had mono- or multiplesystem neuropathy in his small series (three of four patients). Even in HCV CG patients with clinical mono or multiple neuropathy, electrophysiological study revealed a greater than predicted involvement of the peripheral nervous system. [22] These findings imply that the same pathogenic process of nerve destruction causes variable degrees of damage depending on whether the patient has $\mathrm{HCV} \mathrm{CG}$ or $\mathrm{HCV} \mathrm{CG}+$. According to laboratory findings, $\mathrm{HCV} \mathrm{CG}+$ patients had higher RF+ and lower C4 levels than HCV CG patients. These findings confirm prior literature and indicate that complement activation and consumption are likely to occur as a result of immunocomplex formation.[23] When compared to these patients, the vast majority of HCV-CG ones showed no evidence of RF positivity and normal $\mathrm{C} 4$ readings, including the four in Lidove's study.

In our study 25 patients underwent nerve biopsy (20 CG patients and 5 non CG). Prevalence of epineurial vasculitis and fascicular loss of axons was higher in non CG patients while demyelination + axonal degeneration were prevalent in $\mathrm{CG}$ patients. $\mathrm{HCV} \mathrm{CG}+$ and $\mathrm{CG}$ patients had pathological signs of a vasculitic process, according to our findings. Neuropathy can be caused by ischaemia if there is either epineurial vasculitis or fascicular axonal loss.[22,24] MCV of the deep peroneal nerve in patients with $\mathrm{CG}+$ was low as compared to non CG. Even though no statistically significant differences were detected, the other neurophysiological measures pointed to a more extensive and severe involvement of peripheral nerve in $\mathrm{CG}+$ patients. We observed a substantial fibre loss in $\mathrm{CG}_{+}$ compared with CG- patients ( $p<0.005$, $t$ test), as well as in percentage of big myelinated fibres ( $p<0.005$, $t$ test). Total number of clusters, signifying regenerated fibres, was significantly enhanced in CG- compared with CG+ individuals. Antibodies called cryoglobulins can activate the complement system, resulting in vasculitis. With regards to 
the pathophysiology of HCV CG neuropathy's vasculitic process, there are three possible mechanisms for activating the complement: one is caused by the virus' ability to activate the complement pathway; another is based on the reactivity of natural killer cells against viral proteins; and the third is based on the existence of an interaction between $\mathrm{HCV}$ and anti-HCV antibodies. The presence of CG in the serum isn't necessary for the development of vasculitis due to immunocomplex deposition. Natural killer cells are known to be inhibited by the primary HCV envelope protein.[25,26]

To summarize, we found that individuals with HCV $\mathrm{CG}+$ had more severe impairments than those with $\mathrm{CG}$, as measured by clinical, electrophysiological and histometrical studies. Clinical and anatomical evidence suggests that the cause of peripheral nerve injury is vasculitic in $\mathrm{CG}_{+}$and CG patients. When CG is found in the blood, it indicates a more serious and extensive neuropathy, but there is some evidence to suggest that cryoglobulins are not the only cause in the vasculitic reaction.

\section{CONCLUSION}

We concluded in this study that the association of peripheral neuropathy in $\mathrm{HCV}$ patients with cryoglobulinaemia was greater as compared to non-CG HCV patients. It appears that both $\mathrm{CG}_{+}$and $\mathrm{CG}$ patients suffer from peripheral nerve injury via a vasculitic mechanism, as evidenced by clinical and morphological observations. Serum CG levels indicate a more severe and broad neuropathic involvement, however research suggests that cryoglobulins are not the only element in the vasculitic process.

\section{REFERENCE}

1. Lauer G M, Walker B D. Hepatitis $C$ virus infection. $N$ Engl J Med 200134541-52.

2. Gumber S C, Chopra S. Hepatitis C: a multifaceted disease. Review of extrahepatic manifestations. Ann Intern Med 1995123615-620.

3. Apartis E, Leger J M, Musset L.et al Peripheral neuropathy associated with essential mixed cryoglobulinaemia: a role for hepatitis C virus infection? J Neurol Neurosurg Psychiatry 199660661-666.

4. Lidove $\mathrm{O}$, Cacoub P, Maisonobe T.et al Hepatitis $\mathrm{C}$ virus infection with peripheral neuropathy is not always associated with cryoglobulinaemia. Ann Rheum Dis 200160290-292.

5. Nemni R, Sanvito L, Quattrini A.et al Peripheral neuropathy in hepatitis $C$ virus infection with and without cryoglobulinaemia. $J$ Neurol Neurosurg Psychiatry 2003741267-1271.

6. Agnello V, Chung R T, Kaplan L M. A role for hepatitis $C$ virus infection in type II cryoglobulinemia. $N$ Engl $J$ Med 19923271490-1495.

7. Agnello V, Abel G. Localization of hepatitis C virus in cutaneous vasculitic lesions in patients with type II cryoglobulinemia. Arthritis Rheum 1997402007-2015.

8. Bonetti B, Scardoni M, Monaco S.et al Hepatitis C virus infection of peripheral nerves in type II cryoglobulinaemia. Virchows Arch 1999434533-535.

9. Bonetti B, Invernizzi F, Rizzuto N.et alT-cell-mediated epineurial vasculitis and humoral-mediated microangiopathy in cryoglobulinemic neuropathy. $J$ Neuroimmunol 199773145-154.
10. Authier F J, Bassez G, Payan C.et al Detection of genomic viral RNA in nerve and muscle of patients with HCV neuropathy. Neurology 200360808-812.

11. Ripault M P, Borderie C, Dumas P.et alPeripheral neuropathies and chronic hepatitis $\mathrm{C}$ : $\mathrm{a}$ frequent association? Gastroenterol Clin Biol 199822891-896.

12. Cacoub P, Renou C, Rosenthal E.et al Extrahepatic manifestations associated with hepatitis $C$ virus infection. $A$ prospective multicenter study of 321 patients. The GERMIVIC. Groupe d'Etude et de Recherche en Medecine Interne et Maladies Infectieuses sur le Virus de l'Hepatite C. Medicine (Baltimore) 20007947-56.

13. F. Dammacco, D. Sansonno, C. Piccoli, V. Racanelli, F. P. D'Amore, and G. Lauletta, "The lymphoid system in hepatitis $C$ virus infection: autoimmunity, mixed cryoglobulinemia, and overt B-cell malignancy," Seminars in Liver Disease, vol. 20, no. 2, pp. 143-157, 2000.

14. N. F. Fletcher and J. A. McKeating, "Hepatitis $C$ virus and the brain," Journal of Viral Hepatitis, vol. 19, no. 5, pp. 301-306, 2012.

15. D. Sansonno and F. Dammacco, "Hepatitis C virus, cryoglobulinaemia, and vasculitis: immune complex relations," Lancet Infectious Diseases, vol. 5, no. 4, pp. 227236, 2005.

16. R. Sargur, P. White, and W. Egner, "Cryoglobulin evaluation: best practice?" Annals of Clinical Biochemistry, vol. 47, no. 1, pp. 8-16, 2010.

17. S. J. Robbins, A. A. M. Shaheen, and R. P. Myers, "Immunologic complications of the hepatitis C virus," Current Hepatitis Reports, vol. 6, no. 4, pp. 138-144, 2007.

18. alvatore Monaco, Sergio Ferrari, Alberto Gajofatto, Gianluigi Zanusso, Sara Mariotto, "HCV-Related Nervous System Disorders", Journal of Immunology Research, vol. 2012, Article ID 236148, 9 pages, 2012.

19. R Nemni, L Sanvito, A Quattrini, G Santuccio, M Camerlingo, $\mathrm{N}$ Canal. Peripheral neuropathy in hepatitis $C$ virus infection with and without cryoglobulinaemia. J Neurol Neurosurg Psychiatry 2003;74:1267-1271

20. Santoro L, Manganelli F, Briani $C$, et al. Prevalence and characteristics of peripheral neuropathy in hepatitis $C$ virus population. J Neurol Neurosurg Psychiatry. 2006;77(5):626629. doi:10.1136/jnnp.2005.081570

21. Nemni R, Sanvito L, Quattrini A, et al Peripheral neuropathy in hepatitis $\mathrm{C}$ virus infection with and without cryoglobulinaemia Journal of Neurology, Neurosurgery \& Psychiatry 2003;74:1267-1271.

22. Lidove $\mathrm{O}$, Cacoub $\mathrm{P}$, Maisonobe $\mathrm{T}$, et al. Hepatitis $\mathrm{C}$ virus infection with peripheral neuropathy is not always associated with cryoglobulinaemia. Ann Rheum Dis 2001;60:290-2.

23. Trejo $O$, Ramos-Casals $M$, Garcì-Carrasco $M$, et al Cryoglobulinemia. Study of etiologic factors and clinical and immunologic features in 443 patients from a single center. Medicine 2001;80:252-62

24. Paoletti $V$, Donnarumma $L$, De Matteis $A$, Mammarella $A$, Labbadia G, Musca A, Francia A. Peripheral neuropathy without cryoglobulinemia in patients with hepatitis $C$ virus infection. Panminerva Med. 2000 Sep;42(3):175-8.

25. P. Vermeersch, K. Gijbels, G. Mariën, R. Lunn, W. Egner, P. White, et al. A critical appraisal of current practice in the detection, analysis, and reporting of cryoglobulins. Clin Chem, 54 (2008), pp. 39-43

26. ManalAly Abdel Khalek ${ }^{\mathrm{a} A m a l}$ MohamadEI-barbary ${ }^{\mathrm{a}}$ Ferial SalahElkalla ${ }^{\mathrm{b} S a l w a}$ Abdel-MoneimEssa ${ }^{\mathrm{c}}$. Prevalence of peripheral neuropathy in Egyptian hepatitis $C$ virus patients: Correlation to some clinical and laboratory parameters. Received 24 January 2012, Accepted 2 April 2012, Available online 19 May 2012. 